\title{
GERAKAN SOSIAL BARU DI RUANG PUBLIK VIRTUAL
}

\author{
Abdulloh Fuadi; Tasmin \\ IAIN Mataram, Indonesia \\ voeadi@gmail.com
}

The era of information technology that has developed dynamically in recent years has brought significant changes in the way to communicate and mobilize the masses. Public spaces that were once confined to a certain space and time, are now eliminated by the latest technology, to give birth to unlimited public space and can be accessed by anyone, anywhere and anytime. Public space is called virtual public space. The sophistication and effectiveness of this virtual public space is increasingly apparent when a new social movement is able to use it. One of the new social movements was called the National Movement for Guards Fatwa (GNPF) of the Indonesian Ulama Council (MUI) which was born around the end of 2016. This paper tried to examine the MUI GNPF as a new social movement that managed to make maximum use of virtual public space. Felt until now, a year later. In general, this paper is divided into two. The first part discusses the actions of the MUI's GNPF and a series of Islamic Defending Action. The second part discusses virtual public space which is used as the main means for the GNPF MUI in its movement to mobilize the masses.

Key Words: New Social Movement, Fatwa, Public Space

\begin{abstract}
Abstrak
Era teknologi informasi yang begitu berkembang secara dinamis pada tahun-tahun terakhir ini membawa perubahan signifikan dalam cara berkomunikasi dan memobilisasi massa. Ruang publik yang dahulu tersekat dalam ruang dan waktu tertentu, kini tereliminasi oleh teknologi mutakhir, hingga melahirkan sebuah ruang publik tak terbatas dan bisa diakses oleh siapa pun, dimana pun dan kapan pun. Ruang publik itu bernama ruang publik virtual. Kecanggihan dan efektivitas ruang publik virtual ini semakin nyata terlihat kala sebuah gerakan sosial baru mampu memanfaatkannya. Salah satu gerakan sosial baru itu bernama Gerakan Nasional Pengawal Fatwa (GNPF) Majelis Ulama Indonesia (MUI) yang lahir sekitar akhir tahun 2016. Makalah ini mencoba menelaah GNPF MUI sebagai sebuah gerakan sosial baru yang berhasil memanfaatkan secara maksimal ruang publik virtual sehingga gemanya masih sangat terasa hingga kini, setahun kemudian. Secara umum, makalah ini terbagi dua. Bagian pertama membahas sepak terjang GNPF MUI dan rentetan Aksi Bela Islam. Bagian kedua membahas seputar ruang publik virtual yang dipakai sebagai sarana utama bagi GNPF MUI dalam gerakannya memobilisasi massa.
\end{abstract}

Kata Kunci: Fatwa, Gerakan Sosial Baru, Ruang Publik

PENDAHULUAN: GNPF MUI dan Aksi Bela Islam

Aksi Bela Islam adalah rangkaian aksi unjuk rasa yang diadakan di Jakarta sebagai reaksi atas pernyataan gubernur Jakarta saat itu, Basuki Tjahaja Purnama, yang mengeluarkan pernyataaan yang dianggap menistakan agama. Pada 27 September 2016, Gubernur Daerah 
Khusus Ibukota (DKI) Jakarta, Basuki Tjahaja Purnama, melakukan kunjungan kerja ke Pulau Pramuka yang berlokasi di Kepulauan Seribu. Kunjungan ini dilakukan untuk melakukan peninjauan serta pengarahan terkait program pemberdayaan budi daya ikan kerapu yang ia adakan. Dalam pernyataannya, Basuki berusaha meyakinkan warga bahwa programnya akan terus berjalan meski ia tidak terpilih sebagai Gubernur pada Pemilihan Gubernur DKI Jakarta yang berlangsung pada Februari 2017. Sebagaimana kebiasaan dalam rapat dan kunjungan kerja, video aktivitas Basuki ini pun diunggah melalui akun Youtube pemerintah Provinsi DKI Jakarta.

Pada 6 Oktober 2016, seorang netizen bernama Buni Yani mengunggah ulang di halaman Facebooknya kutipan video yang berjudul 'Penistaan Terhadap Agama?'. Video ini merupakan editan dari video kunjungan kerja Basuki dengan lebih menonjolkan pernyataan yang mengandung unsur penistaan terhadap agama Islam. Video ini akhirnya ditonton oleh banyak orang dan menyulut emosi umat Islam yang tidak sudi kitab suci dan ulamanya dihina. Sebagai respon dari video ini, banyak dari ormas Islam di penjuru Indonesia mengirimkan pengaduan kepada kepolisian agar segera menindaklanjuti pernyataan Basuki tersebut.

Pada 10 Oktober 2016, Basuki meminta maaf kepada publik karena telah menimbulkan kegaduhan. Beberapa tokoh Islam menyatakan menerima pernyataan maaf yang ia ajukan namun menambahkan bahwa proses hukum harus tetap berjalan. Pada 11 Oktober 2016, MUI mengeluarkan Pendapat dan Sikap Keagamaan tentang kasus dugaan
Volume 1 Nomor 1 Tahun 2018 penistaan agama yang dilakukan oleh Gubernur DKI Jakarta Basuki Tjahaya Purnama atau yang lebih dikenal dengan nama Ahok. Pendapat dan Sikap Keagamaan MUI terdiri dari 5 poin:

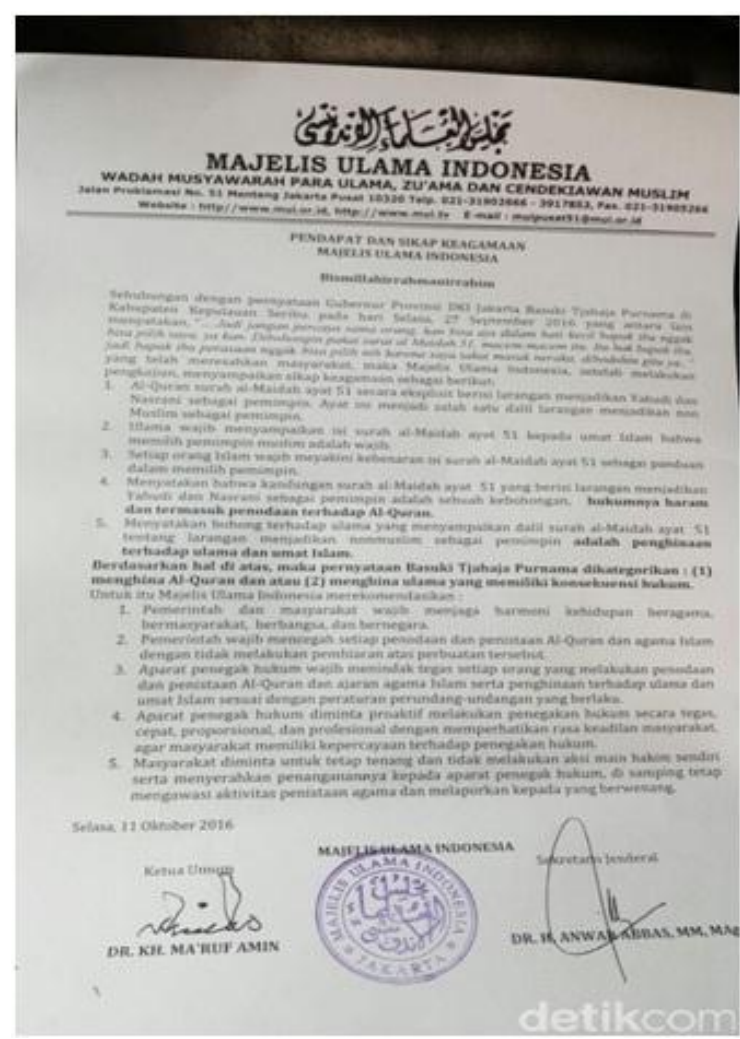

1. Al-Quran surah al-Maidah ayat 51 secara eksplisit berisi larangan menjadikan Yahudi dan Nasrani sebagai pemimpin.

2. Ulama wajib menyampaikan isi surah al-Maidah ayat 51 kepada umat Islam bahwa memilih pemimpin muslim adalah wajib.

3. Setiap orang Islam wajib meyakini kebenaran isi surah al-Maidah ayat 51 sebagai panduan dalam memilih pemimpin.

4. Menyatakan bahwa kandungan surah al-Maidah ayat 51 yang berisi larangan menjadikan Yahudi dan Nasrani sebagai pemimpin adalah sebuah kebohongan, hukumnya haram dan termasuk penodaan terhadap Al-Quran.

5. Menyatakan bohong terhadap ulama yang menyampaikan dalil 
Volume 1 Nomor 1 Tahun 2018

surah al-Maidah ayat 51 tentang larangan menjadikan nonmuslim sebagai pemimpin adalah penghinaan terhadap ulama dan umat Islam.

Berdasarkan hal di atas, maka pernyataan Basuki Tjahaja Purnama dikategorikan: (1) menghina Al-Quran dan atau (2) menghina ulama yang memiliki konsekuensi hukum.

Sebagian orang menganggap Pendapat dan Sikap Keagamaan MUI tersebut adalah sebagai Fatwa MUI. Salah seorang Pengurus Pusat MUI, Bachtiar Nasir, mendirikan sebuah gerakan yang bernama Gerakan Nasional Pengawal Fatwa Majelis Ulama Indonesia (GNPF MUI).

\section{Aksi Bela Islam I}

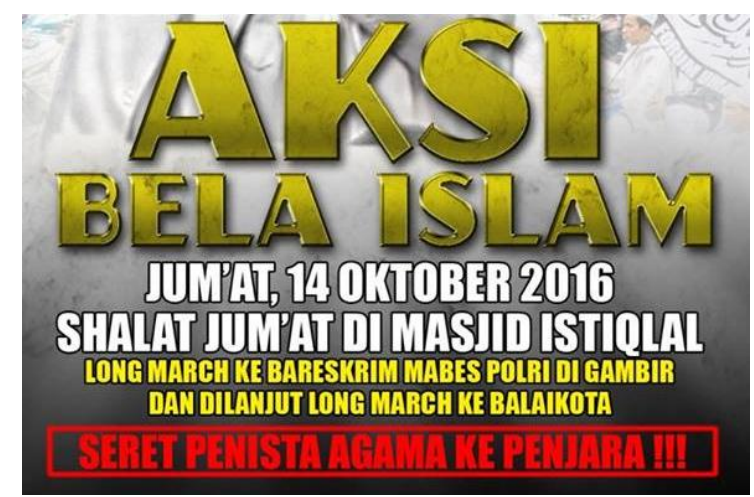

Pada 14 Oktober 2016, seusai shalat Jumat, ribuan ormas Islam yang dikomandoi oleh Front Pembela Islam (FPI) melakukan aksi unjuk rasa di depan Balai Kota DKI Jakarta. Dalam aksinya, mereka menuntut agar penyelidikan atas kasus penistaan agama yang dilakukan oleh Gubernur DKI Jakarta, Basuki Tjahaja Purnama segera dilakukan. Habib Rizieq Shihab sebagai pimpinan FPI mengancam akan melakukan aksi yang lebih besar jika tidak kunjung merespon kasus ini dalam 3 minggu berikutnya.
Berbagai macam respon muncul menanggapi unjuk rasa ini, mulai dari yang mendukung sampai yang kontra. Basuki sendiri menyoroti kerusakan taman yang dinyatakan akibat ulah para pengunjuk rasa.

2. Aksi Bela Islam II

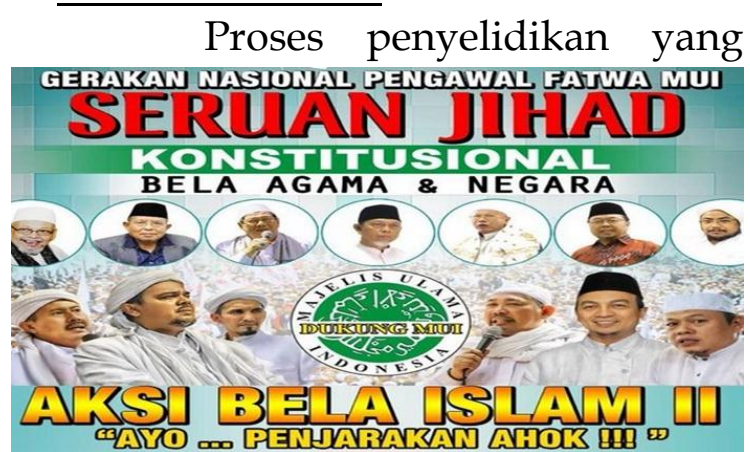

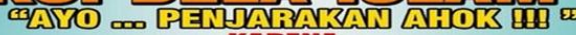

dianggap berjalan sangat lamban membuat ormas Islam kembali menghimpun massa dalam jumlah yang lebih besar. Berbagai pesan disebarkan melalui media sosial untuk mengundang masyarakat hadir dan turut serta dalam unjuk rasa Aksi Bela Islam II yang lebih dikenal dengan 'Aksi Damai 411'. Pada awal November 2016, para pengunjuk rasa yang berasal dari luar daerah mulai berduyun-duyun datang menuju DKI Jakarta untuk menghadiri aksi ini.

Pada 4 November 2016, aksi unjuk rasa ini kembali diadakan dengan jumlah massa yang sangat besar. Aksi ini dimulai usai shalat Jumat dan menjadikan posisi di depan Istana Negara sebagai pusatnya. Kali ini para pengunjuk rasa berusaha agar tidak melakukan pengrusakan dan menjaga kebersihan agar tidak dikritik sebagaimana demo sebelumnya. Selain di Jakarta, aksi serupa juga diadakan di beberapa kota lainnya di Indonesia. 
Di Jakarta, perwakilan dari pengunjuk rasa diberikan kesempatan untuk bertemu dengan Menkopolhukam, Wiranto, dan Wakil Presiden Republik Indonesia, Jusuf Kalla, untuk mendiskusikan jalan keluar terkait kasus penistaan agama yang melibatkan Gubernur DKI Jakarta, Basuki Tjahaya Purnama. Pengunjuk rasa juga menuntut untuk bertemu dengan Presiden Republik Indonesia, Joko Widodo, dan meminta agar Presiden tidak mengintervensi penyelidikan kasus ini. Pada saat itu, Presiden sedang tidak berada di istana negara dengan alasan kunjungan untuk meninjau pembangunan stasiun kereta api di bandara SoekarnoHatta.

Pada tengah malam 5 November 2016, Presiden Joko Widodo mengadakan konferensi pers di istana negara dan menyatakan sikapnya terkait kasus penistaan agama oleh Basuki Tjahaja Purnama. Ia bersama kepolisian berkomitmen untuk menuntaskan kasus ini dalam waktu yang cepat dan juga dilaksanakan setransparan mungkin. Ia juga menambahkan bahwa ada aktor politik yang bermain sehingga menimbulkan kericuhan pada aksi kali ini. Penyelidikan mulai intensif dilakukan dengan memanggil saksi dari para pelapor dan pihak terlapor. Pada 15 November 2016, dilakukan gelar perkara secara terbuka terbatas untuk menentukan status hukum bagi Basuki Tjahaja Purnama. Pada 16 November 2016, kepolisian menetapkan Basuki sebagai tersangka kasus penistaan agama. Namun berdasarkan sejumlah pertimbangan, diputuskan bahwa Basuki tidak ditahan di penjara,
Volume 1 Nomor 1 Tahun 2018 hanya paspornya ditahan sehingga tidak bisa ke luar negeri. Hal ini membuat geram sejumlah pihak.

\section{Aksi Bela Islam III (Aksi 212)}

Aksi 212 yang digawangi Gerakan Nasional Pengawal Fatwa Majelis Ulama Indonesia (GNPF MUI) ini menuntut Kepolisian untuk memproses kasus dugaan penistaan agama yang dilakukan Ahok. Meskipun yang bersangkutan akhirnya ditetapkan sebagai tersangka,

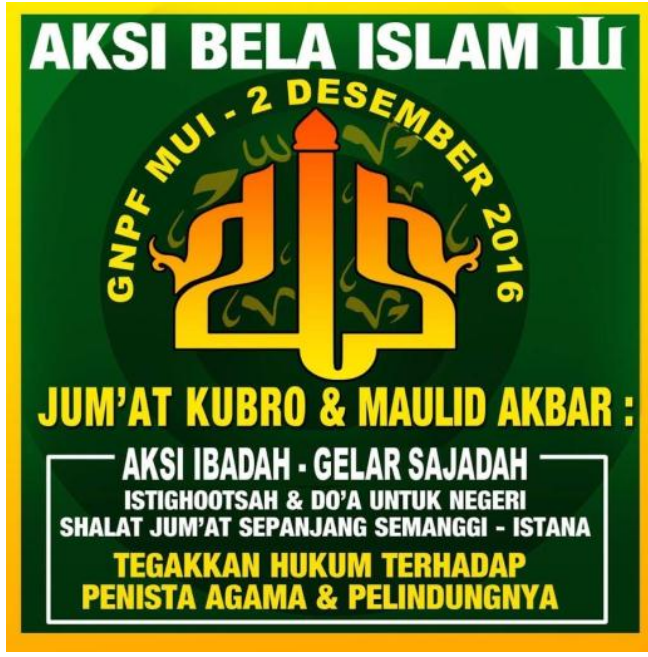

namun GNPF MUI menginginkan Ahok dibui. GNPF MUI menilai, bebasnya Ahok, meski berstatus tersangka, terasa aneh dan tak adil.

Awalnya, mereka berencana untuk menggelar sajadah di sepanjang Jalan $\mathrm{MH}$ Thamrin hingga Semanggi untuk melaksanakan ibadah. Namun, setelah bertemu dengan pihak kepolisian, lokasinya diubah ke Monas. Dalam kesepakatan bersama antara kedua pihak, Muhammad Rizieq Shihab selaku Imam Besar Front Pembela Islam (FPI) meyakinkan masyarakat kalau aksi ini akan berlangsung damai. Para peserta hanya akan menjalankan ibadah bersama, dari 
Volume 1 Nomor 1 Tahun 2018 pukul 8 pagi hingga usai salat Jumat (Rappler, Memahami aksi 212, apakah akan berjalan damai? (https://www.rappler.com

/indonesia/berita/154 269-aksi-damai-2desember-silang-monas), diakses pada 1 Nopember 2017). Bahkan Presiden Joko Widodo pun hadir dalam acara ini dan disambut hangat oleh para peserta aksi. Menurut rilis resmi Gerakan Nasional Pengawal Fatwa Majelis Ulama Indonesia (GNPF-MUI), forum yang menyelenggarakan acara ini, jumlah umat yang hadir di Monas berkisar $6-7$ juta orang.

Aksi 212 ini seakan melahirkan kepemimpinan baru pemimpin agama di samping ulama-ulama organisasi massa Islam mainstream. Aksi ini membangkitkan semangat keagamaan umat Islam. Dari liputan media terlihat sebagian umat Islam menyediakan bekal perjalanan. Di pinggir jalan tampak tersedia nasi bungkus, air kemasan dan segala macam penganan (Tempo, Dari 411 ke 212 (https://indonesiana.tempo.co/ read/101942/ 2016/ 12/01/Dari-411-ke-212), diakses pada 1 Nopember 2017).

Menurut Ahmad Kholili Hasib, setidaknya ada lima alasan mengapa fenomena menarik dari Aksi 212 ini terjadi. Pertama, Aksi 411 dan 212 menunjukkan kualitas ukhuwah umat Islam. Semangat rahmat lil alamin ditampilkan secara riil. Sekelompok non-Muslim yang datang ke Monas mengaku nyaman dan aman. Jamaah 212 pun saling mengingatkan, "Jangan injak rumput, jangan injak taman, jaga kebersihan!" Mereka adalah orang-orang Islam yang berlatar belakang orang biasa, tetapi kepeduliannya pada agama luar biasa. Mereka tidak banyak bicara, karena tidak memiliki panggung. Bukan orang berpengaruh, karena memang tidak punya pengaruh. Kedua, Aksi 411 dan 212 menunjukkan bukti, sifat Islam itu bergerak. Umat Islam ibarat sumber api yang tertutup semak dan jerami. Dari luar nampak apinya sudah padam, tetapi sesungguhnya ia masih tetap menyala. Api itu akan siap menyambar apa saja, selama ada pemicunya. Selama sumber itu masih ada, sewaktu-waktu akan membakar sekitarnya. Ketiga, Aksi 411 dan 212 menunjukkan fakta, umat Islam lebih percaya ulama yang tulus. Empat, Jamaah Medsos sebagai sumber informasi. Fenomena Aksi 411 dan 212, juga menemukan fakta, umat Islam lebih memilih sumber informasi lansung melalui jejaring sosial. Facebook, Twitter dan WhatsApp menjadi rujukan utama dan tercepat mencari dan menemukan informasi. Lima, fenomena lahirnya generasi baru Islam di Indonesia. Lahirnya gerakan baru intelektual Muslim yang terlepas dari sekat-sekat organisasi (Ahmad Kholili Hasib, Aksi 212 dan 5 Fenomena Lahirnya Generasi Baru Islam Indonesia (https://www.hidayatullah.com/artikel/ghazw ul-fikr/read /2016/ 12/08/107231/aksi-212dan-5-fenomena-lahirnya-generasi-baruislam-indonesia.html, 8 Desember 2016), diakses pada 1 Nopember 2017).

4. Aksi Bela Islam IV

Aksi 112 atau yang disebut juga Aksi 11 Februari dan Aksi Bela Islam IV merupakan aksi damai lanjutan dari Aksi Bela Islam I, II, dan III. Aksi ini dikoordinasi oleh Forum Umat 
Islam (FUI) dan juga Gerakan Nasional Pengawal Fatwa Majelis Ulama Indonesia (GNPF-MUI). Awalnya, aksi 112 akan dilaksanakan di Lapangan Monas Jakarta. Akan tetapi, bentuk acara diubah menjadi zikir dan tausiah di Masjid Istiqlal Jakarta setelah Ketua Front Pembela Islam (FPI), Muhammad Rizieq Shihab dan pemimpin GNPF-MUI bertemu dengan Menkopolhukam Wiranto. Peserta mulai berdatangan ke lokasi sejak Jum'at malam dan kegiatan dimulai sejak salat tahajud pukul 2.00 WIB, salat subuh berjamaah, salat duha dan kegiatan zikir bersama dan tausiah dari ulama nasional hingga berakhir setelah melaksanakan salat zuhur secara berjamaah. Peserta berjumlah lebih dari 200 ribu jamaah. Tujuan aksi 112 ini yaitu memastikan dukungan penduduk Jakarta untuk menolak penodaan AlQuran, menolak kriminalisasi dan penghinaan terhadap ulama, menjaga pilkada yang jujur dan adil, dan mewajibkan memilih kepala daerah yang muslim.

\section{Aksi Bela Islam V}

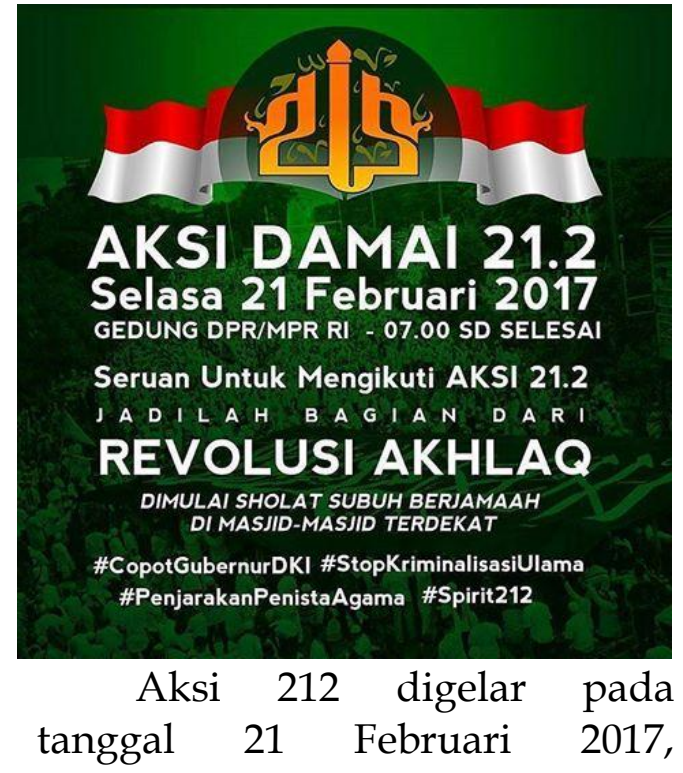

Volume 1 Nomor 1 Tahun 2018 berlangsung di kawasan Gedung Dewan Perwakilan Rakyat Senayan, Jakarta Pusat. Aksi yang digagas oleh Forum Umat Islam (FUI), ini dihadiri oleh Imam Besar Front Pembela Islam, Muhamad Rizieq Shihab, dimulai pukul 08:00 pagi dan dalam keadaan hujan. Menanggapi aksi tersebut, karena dinilai memiliki muatan politik, dua organisasi keagamaan terbesar Indonesia, Nahdlatul Ulama dan Muhammadiyah memilih tidak terlibat. Aksi 212 menuntut:

1) Meminta DPR/MPR melayangkan surat kepada Presiden Republik Indonesia, Joko Widodo terkait penonaktifan Basuki Tjahaja Purnama alias Ahok.

2) Gubernur DKI Jakarta dinilai tidak layak tetap dijabat oleh seseorang dengan status terdakwa kasus dugaan penodaan agama.

3) Meminta aparat penegak hukum tidak melakukan kriminalisasi terhadap ulama dan mahasiswa, serta minta aparat penegak hukum menangkap Ahok.

Atas tuntutan tersebut, Komisi III DPR RI meneruskan kepada pimpinan DPR, untuk dapat diteruskan kepada Presiden, serta melaporkan kepada Kapolri, Jendral Tito Karnavian pada rapat kerja dengan Komisi III, 22 Februari 2017.

\section{Aksi Bela Islam VI}

Aksi 31 Maret atau Aksi 313 adalah gerakan massa yang diselenggarakan di Jakarta, pada tanggal 31 Maret 2017, diinisasi oleh Forum Umat Islam (FUI) dan 
Volume 1 Nomor 1 Tahun 2018 diikuti oleh berbagai kelompok organisasi massa Islam. Aksi ini melakukan long march dari Masjid Istiqlal menuju Istana Merdeka dengan tujuan meminta Presiden Joko Widodo agar memberhentikan Basuki Tjahaja Purnama alias Ahok dari jabatannya sebagai Gubernur Daerah Khusus Ibukota Jakarta. Pada saat aksi berlangsung, Presiden Joko Widodo sedang menemui Ketua Majelis Ulama Indonesia (MUI) KH MA'ruf Amin.

Menurut rencana semula, aksi 31 Maret yang diinisasi oleh Forum Umat Islam dan diikuti oleh berbagai kelompok organisasi massa Islam, ini menjadikan Masjid Istiqlal sebagai titik kumpul. Setelah itu mereka berjalan kaki menuju Istana Merdeka melalui Jalan Merdeka Timur, menuju depan Kedutaan Besar Amerika Serikat, kemudian ke Jalan Merdeka Selatan, melewati Balai Kota. Aksi ini juga menelusuri jalan protokol di seputaran Patung Kuda. Sesampai di Istana Merdeka, massa 313 menggelar orasi dan menyampaikan sejumlah tuntutan, terutama mengingatkan kepada Presiden Joko Widodo untuk memberhentikan Basuki Tjahaja Purnama alias Ahok dari jabatannya sebagai Gubernur DKI Jakarta, sebagaimana tertuang dalam Undang-Undang nomor 23 Tahun 2014 tentang pemerintah daerah. Namun akhirnya aksi massa 313 batal berorasi di depan Istana Merdeka, Jalan Medan Merdeka Utara, Jakarta Pusat. Pengunjuk rasa hanya diperbolehkan melakukan longmarch sampai dengan kawasan Patung Kuda dan berorasi di sana, sebab polisi telah menseterilkan kawasan di sekitar Istana Merdeka hingga ke Jalan Medan Merdeka Barat. Sterilisasi kawasan Istana dari pengunjuk rasa yang dilakukan oleh Polda Metro Jaya ini, menurut Kadiv Humas Polri Irjen Boy Rafli Amar, sudah sesuai dengan prosedur. Selanjutnya, perwakilan pengunjuk rasa yang melibatkan massa dari berbagai elemen ini akhirnya diterima di kantor Menkopolhukam, Jalan Medan Merdeka Barat, bukan di istana.

\section{Aksi Bela Islam VII}

Gerakan Nasional Pengawal Fatwa MUI kembali menggelar aksi menjelang vonis terdakwa penistaan agama Basuki Tjahaja Purnama alias Ahok. GNPF mengklaim 5 juta orang hadir dalam aksi yang diselenggarakan Jumat, 5 Mei 2017 itu. GNPF menggelar aksi menuntut agar Ahok dipenjarakan. Juru Bicara Forum Umat Islam, Bernard Abdul Jabar, ketika itu mengancam akan membawa massa lebih besar jika hakim tidak memenuhi tuntutan mereka.

Ahok menjalani sidang vonis pada 9 Mei. Gubernur DKI Jakarta itu dituntut jaksa hukuman percobaan dua tahun karena pernyataannya soal surat $\mathrm{Al}$ Maidah 27 September 2016 lalu terbukti mengandung permusuhan, kebencian, atau penghinaan terhadap satu atau beberapa golongan. Menurut Jaksa, pernyataan Ahok ini dikaitkan dengan Pilkada DKI Jakarta 2017. 
Seruan aksi 5 Mei itu telah tersebar di media sosial. Dalam seruan aksi berbentuk poster tertulis: Alumni 212 dan semuanya hadirilah Aksi Bela Islam 55. Aksi dilakukan usai salat Jumat di Masjid Istiqlal, Jakarta dan dilanjutkan dengan long march menuju Mahkamah Agung. Aksi damai dan simpatik ini bertujuan menjaga keadilan hukum. "Ahok penista agama Islam harus dihukum maksimal," demikian tertulis dalam poster seruan aksi. GNPF berulang kali menggelar Aksi Bela Islam sejak kasus penistaan agama mencuat (S. Yugo Hindarto, GNPF Akan Gelar Aksi Bela Islam 55, (https://www.cnnindonesia.com/nasional/ 20170502092141-20-211501/gnpf-akangelar-aksi-bela-islam-55/, 2 Mei 2017), diakses pada 1 Nopember 2017.).

Gerakan Nasional Pengawal Fatwa Majelis Ulama Indonesia (GNPF-MUI) menyatakan bahwa aksi 5 Mei menjadi penutup sejumlah aksi bela Islam yang sebelumnya telah dilakukan beberapa kali. Wakil Ketua GNPF-MUI, Zaitun Rasmin pun menyatakan tidak akan ada lagi upaya pengerahan massa turun ke jalan terkait kasus penodaan agama yang menjerat Basuki Tjahaja Purnama atau Ahok (http://news.liputan6.com/read/2942281/gnpf -mui-aksi-5-mei-jadi-penutup-aksi-belaislam, diakses pada 1 Nopember 2017).

Dalam perkembangannya, GNPF-MUI tidaklah berhenti bergerak begitu Aksi Bela Islam VII selesai. Pada tanggal 30 Oktober 2017, bertempat di hotel Sahid Jakarta, Gerakan Nasional Pengawal Fatwa MUI resmi mengumumkan perubahan nama menjadi Gerakan Nasional Pengawal Ulama. Istilah ulama dipakai untuk
Volume 1 Nomor 1 Tahun 2018 menghilangkan beban bagi Majelis Ulama Islam (MUI) sebagai sebuah institusi organisasi. Meskipun perubahan nama terjadi, tetapi jajaran personel dan jabatan masing-masing tidaklah berubah, termasuk Muhammad Rizieq Shihab sebagai salah satau dewan pembina (https://suarapelita.com/2017/10/30/resmi-gnpfmui-bubar-ganti-nama-menjadi-gnpf-ulama/, diakses pada 1 Nopember 2017).

\section{GERAKAN SOSIAL BARU: GNPF MUI dan Ruang Publik Virtual}

Perkembangan kontemporer menunjukkan bahwa ruang publik mengalami perkembangan pesat seiring tumbuhnya ICT (information communication technology) yang melahirkan ruang publik virtual. Ruang ini begitu menarik karena merupakan 'ruang imajiner' atau 'maya' yang bersifat artifisial, dimana setiap orang dapat melakukan apapun yang biasa dilakukan dalam kehidupan sosial sehari-hari tapi dengan cara yang baru. Hal-hal menarik tersebut antara lain adalah: (1) identitas aktor-aktor sosial tersembunyi di balik tanda; (2) isu-isu politik tersebar dengan cepat dan menjangkau penerima yang amat luas tanpa dibatasi ruang dan waktu; (3) masyarakat diarahkan untuk mengembangkan hidupnya melalui jejaring (the network society).

Dalam konteks masyarakat jaringan (network society), identitas menjadi isu penting. Kerangka globalisasi menjadikan batas-batas teritorial menjadi semakin cair. Globalisasi menyediakan mekanismenya sendiri melalui teknologi komunikasi yang kian canggih dan kian cepat menyebarluaskan informasi dan ini memperluas pilihan arah atau kiblat. Globalisasi dengan segala mekanismenya telah membukakan 
Volume 1 Nomor 1 Tahun 2018

pintu yang sangat luas untuk memandang dunia, memilih, mengambil dan menginginkan caracara hidup yang dipandang sesuai. Konsep 'mengglobal' inilah yang akhirnya membuka jaringan yang semakin luas. Dalam dunia networking pemaknaan dapat muncul dari berbagai sumber. Kapitalisme yang masuk bersama globalisasi menyediakan sebuah tempat yang lapang bagi konstruksi identitas (Dwi Wulan Pujiriyani, 2013).

Keterhubungan antara individu dan kelompok dalam network society bersifat sangat cair di mana satu individu bisa berinteraksi dengan berbagai sumber. Model masyarakat terhubung inilah yang kemudian membawa dampak besar dalam berbagai bidang kehidupan. Setidaknya ada enam bidang yang terpengaruh dengan sistem yang diterapkan dalam network society yaitu bidang ekonomi, politik dan kekuasaan, hukum, struktur sosial, budaya, dan psikologi. Di dalam network society, informasi menjadi pusat dari keterkaitan antara berbagai elemen dalam masyarakat (Ressi Dwiana, 2013).

\section{Grup-grup diskusi maupun} forum perbincangan politik maupun aksi-aksi sebagai respon dari realitas politik di daring merupakan salah satu perwujudan ruang publik di era internet saat ini sebagai pengganti ruang baca, perpustakaan, kafe, dan tempat-tempat lain yang telah menjelma menjadi sebagai virtual sphere atau ruang virtual. Ruang virtual yang memfasilitasi publik untuk melakukan interaksi melalui beragam jenis komunikasi internet.

Melalui pendekatan kultural, ruang publik virtual melahirkan budaya baru dalam proses demokratisasi. Tidak ada lagi batasan antara borjuis dan proletar, batasan gender menjadi kabur, dan siapa saja bisa melibatkan dirinya dalam debat intelektual di ranah politik. Sebuah isu bahkan bisa menjadi informasi yang sangat cepat tersebar dan langsung bisa dijadikan topik perdebatan. Juga, ini merupakan efek yang tidak bisa terelakkan, ruang virtual menyuburkan gerakan yang beragam, mulai dari gerakan akar rumput hingga aktivitas terorisme yang menggunakan internet sebagai ruang bebas untuk menyebarkan paham dan keyakinan tentang kekuasaan pemerintah saat ini, termasuk di Indonesia (Rulli Nasrullah, 2012)

Beberapa pandangan berikut menunjukkan betapa ruang publik virtual tersebut menyimpan potensi positif dan optimis (cyberoptimist) sekaligus negatif dan pesimis (cyberpessimist). Pandangan pertama memiliki keyakinan bahwa ruang publik virtual mampu membuka kemungkinan luas terbangunnya komunikasi dan interaksi bagi segenap warga negara tanpa sekat-sekat ideologi, etnis, dan agama. Ruang publik virtual memfasilitasi tumbuhnya entitas yang leluasa mengembangkan dialog publik menanggapi isu-isu ketidakadilan, monopoli, serta manipulasi negara dan pasar terhadap masyarakat sipil. Relasi-relasi kekuasaan antara negara, pasar, dan masyarakat sipil tidak lagi mengikuti narasi penguasa dalam membangun jaringannya. Latar belakang demografis atau ideologi politik yang dimiliki oleh entitas menjadi terabaikan ketika berada di ruang virtual. Wacana yang dibangun juga berdasarkan diskusi kritis dan debat yang ilmiah demi kepentingan publik. Pandangan ini juga menekankan bahwa ruang virtual setidaknya telah memberikan 
kesempatan lebih luas bagi entitas untuk bertukar pikiran tentang kepentingan publik. Proses ini pun tidak lepas dari penyadaran diri khalayak yang terlibat dalam ruang virtual.

Pandangan kedua menekankan pada legitimasi yang berada dalam wacana yang dikonstruk dalam debat kritis karena ruang publik yang terjadi adalah ruang publik virtual yang sangat bias dari keterwakilan. Oleh sebab itu, ruang publik yang ada pada dasarnya tidak mewakili siapa pun karena kaburnya identitas dari entitas yang terlibat dalam ruang publik virtual tersebut. Hal ini terutama terkait dengan maraknya fake information (informasi palsu), atau yang biasa disebut dengan istilah hoax. Kritik berikutnya terkait dengan wacana yang dihasilkan dari debat kritis tersebut apakah dapat tersuarakan secara riil sehingga bisa mendapatkan perhatian dari pemegang kekuasaan, yaitu penyelenggara negara dan pemerintah. Arus komunikasi yang berasal dari wacana tersebut bisa saja tidak pernah tersampaikan kepada pengambil keputusan, atau sebaliknya, para pengambil keputusan itu tidak bisa menjangkaunya. Menanggapi kritik ini, perkembangan masyarakat jejaring saat ini membuka peluang bagi semua kalangan dari berbagai latar belakang kelas untuk terlibat aktif dalam diskusi publik dan mengonstruk wacana sebagai respon dari realitas politik atau proses demokratisasi, termasuk para pengambil kebijakan. Meskipun demikian, masih ada juga kritik yang menyatakan bahwa terdapat banyak ruang virtual untuk diskusi atau debat, sehingga para pengguna justru dapat menentukan sendiri pilihannya tentang ruang virtual mana yang mau mereka ikuti.
Volume 1 Nomor 1 Tahun 2018

Gerakan sosial baru, berbeda dengan gerakan sosial lama, memfokuskan pada kaitan isu-isu simbolik dan kebudayaan dengan indentitas. Gerakan sosial lama menyandarkan pada ideologi politik tertentu, sedangkan gerakan sosial baru menerima pluralisme ide serta cenderung mengembangkan pandangan pragmatis dalam upaya menciptakan sistem partisipasi politik seluas-luasnya dalam proses pengambilan keputusan.

Tipe pertama dari gerakan sosial baru adalah memfokuskan pada kaitan isu-isu simbolik dan kebudayaan dengan identitas. Sedangkan tipe kedua menerima pluralisme ide serta cenderung mengembangkan pandangan pragmatis dalam upaya menciptakan sistem partisipasi politik seluas-luasnya dalam proses pengambilan keputusan. Kedua tipe gerakan sosial baru ini muncul pada kasus GNPF MUI. Isu-isu simbolik dan kebudayaan yang dikaitkan dengan identitas sangat terasa karena pembenturan identitas yang diramu sedemikian rupa sehingga umat Islam yang ikut dalam Aksi Bela Islam berhadap-hadapan secara langsung, baik dengan pemerintah, maupun kelompok Islam lain yang tidak menyetujui aksi tersebut.

Tipe kedua dari gerakan sosial baru adalah menerima pluralisme ide serta cenderung mengembangkan pandangan pragmatis. Diskusi mengenai GNPF MUI dan Aksi Bela Islam di berbagai media jejaring sosial mengundang berbagai pihak dari beragam latar belakang untuk membicarakan berbagai masalah yang berkaitan dengan hal tersebut. Berbagai portal dan akun dari bermacam latar belakang kelas sosial, etnisitas, politik, maupun agama turut berdiskusi 
Volume 1 Nomor 1 Tahun 2018

tentang GNPF MUI di akun media sosial, sebagai sebuah media yang keanggotaannya terbuka bagi siapa pun. Pluralisme ide yang merupakan tipe kedua dari gerakan sosial baru pun muncul.

Gerakan sosial baru lebih menaruh perhatian pada life politics dibandingkan emancipatory politis seperti pada gerakan sosial lama. Oleh karenanya, keanggotaan gerakan sosial baru bersifat terbuka tanpa menghiraukan latar belakang kelas sosial, etnisitas, politik, maupun agama. Atas dasar ini, gerakan sosial baru dapat dikategorikan sebagai suatu perkumpulan yang inklusif dan diprakarsai aktor-aktor dan diikuti kelompok-kelompok yang secara sadar memobilisasi diri untuk bersama-sama memperjuangkan democratization of everyday life. Di dalamnya menekankan pentingnya: 1) unsur jaringan yang kuat tetapi interaksinya bersifat informal atau tidak terstruktur, (2) adanya sharing keyakinan dan solidaritas di antara mereka, (3) ada aksi bersama dengan membawa isu yang bersifat konfliktual, dan, (4) aksi tuntutan itu bersifat kontinyu tetapi tidak terinstitusi dan mengikuti prosedur rutin seperti dikenal dalam organisasi (Dewi Kartika Sari \& Royke R. Siahainenia, 2015). GNPF MUI dan berbagai gerakan Aksi Bela Islam menunjukkan keempat hal di atas.

$$
\text { Ruang publik virtual }
$$
tampaknya menjadi sarana utama bagi gerakan sosial baru terkini. Tumbuhnya ICT mampu membuka kembali wacana otonomi dan kebebasan individu, kolektivitas, serta identitas. Di dalam ruang ini, aktoraktor pendukung gerakan kemudian menggunakan teori proses framing untuk memahami sukses dan gagalnya sebuah gerakan sosial. Oleh karena itu, aktor perubahan memiliki tugas penting mencapai perjuangan melalui pembentukan framing atas masalahmasalah sosial dan ketidakadilan yang diperjuangkan. Pembentukan framing ini tergantung dari bagaimana ICT mampu mewadahinya sehingga dapat membentuk ruang publik tanpa campur tangan negara, yang kemudiaan disebut dengan ruang publik virtual itu. Framing semacam ini juga digunakan oleh GNPF MUI dalam melawan kebijakan pemerintah terhadap kasus Ahok dan wacana yang dilontarkan oleh kelompok Islam lain yang tidak sepaham dengan mereka.

Sampai pada titik ini, seseungguhnya apa yang dilakukan oleh GNPF MUI juga dapat dijelaskan melalui tiga konsep kunci dalam teori gerakan sosial yang biasanya memainkan peran yang sangat penting dalam menentukan keberhasilan aksiaksi kolektif. Ketiga konsep itu meliputi (1) struktur kesempatan politik (political opportunity structure), (2) struktur mobilisasi (mobilizing structures), dan (3) pembingkaian aksi (framing). (Hasanuddin, 2011). Konsep struktur kesempatan politik menjelaskan bahwa munculnya gerakan sosial seringkali dipicu oleh perubahan-perubahan signifikan yang terjadi dalam struktur politik dan karenanya, meredupnya gerakan itu juga biasanya berhubungan dengan pergeseran-pergeseran yang terjadi di dalamnya. Dengan kata lain, struktur kesempatan politik berdampak mempercepat terjadinya ataupun mengakhiri aksi kolektif. Namun, struktur kesempatan politik saja tidak cukup mendorong terjadinya aksi kolektif. Ia harus ditopang oleh struktur mobilisasi yang biasanya berakar dalam jaringan-jaringan sosial yang sudah terbangun sebelumnya. 
Melalui jaringan itu massa dan simpatisan direkrut dan dimobilisasi. Keberadaan jaringan rekruitmen memang menjadi penentu dalam proses pelibatan individu, karena mobilisasi tidak berlangsung dalam ruang hampa. Untuk memobilisasi massa itulah aktor-aktor gerakan sosial perlu membingkai aksi-aksi yang mereka rencanakan dengan sloganslogan dan bahasa yang mudah dipahami dan sekaligus dapat menggerakkan sentimen mereka. Di sinilah arti penting framing sebagai seni mengkomunikasikan pesan untuk menggerakkan audien dan memompa dukungan serta partisipasi. Ideologi, sebagai sistem kepercayaan, ide, nilai, dan makna, biasanya bekerja untuk mendukung efektivitas framing ini (Noorhaidi Hasan, 2006).

Dengan demikian, gerakan sosial itu rasional dan muncul karena persentuhannya dengan dinamika politik tertentu, melalui proses mobilisasi yang melibatkan jaringanjaringan rekruitmen yang rumit dan dipoles dengan sentuhan-sentuhan ideologi melalui framing yang tepat. GNPF-MUI secara telak memenuhi ketiga syarat tersebut.

\section{PENUTUP}

GNPF MUI dan rentetan Aksi Bela Islam menunjukkan gejala gerakan sosial baru di Indonesia, dimana ruang publik virtual mampu dimanfaatkan secara maksimal sehingga segala wacana yang dikemukakan oleh media-media mainstream mampu dilawan. Inilah kekuatan media baru yang bisa dimanfaatkan oleh siapa pun. Isu-isu sensitif bisa dikelola sedemikian rupa sehingga mampu memobilisasi massa dalam jumlah yang tak terkirakan. Potensi positif ini mesti dibarengi dengan kewaspadaan bahwa
Volume 1 Nomor 1 Tahun 2018 ada potensi negatif yang terkandung di dalamnya, yaitu terkait dengan fake information (informasi palsu) atau yang bisa diistilahkan dengan hoax. Hoax dimaknai sebagai kepalsuan yang sengaja dibuat untuk menyamar sebagai kebenaran. Hoax bukanlah domain dunia maya dalam ruang publik virtual, bahkan media mainstream pun dapat melakukan hal ini. Dampak dari penyebaran informasi palsu secara massif akan menyebabkan efek yang luar biasa, yaitu berimplikasi pada rapuhnya kepercayaan kepada sebuah kebenaran, serta mampu mengkonstruk false consciousness (kesadaran palsu) pada seseorang atau sebuah komunitas. Setidaknya ada dua solusi dalam mendapatkan data yang otentik dengan tingkat akurasi yang tinggi: pertama, melakukan cross-check dengan informasi dari pihak kedua atau second opinion. Hal ini penting untuk memperkaya wawasan terhadap wacana yang sedang bergulir. Kedua, melakukan cross-check dengan pihak yang bersangkutan secara langsung. Saat dunia virtual dipenuhi dengan informasi yang simpang siur sehingga dapat menurunkan tingkat kepercayaan sampai pada titik nadir, maka cara atau metode tradisional pun tak dapat dihindari, yaitu bertemu langsung secara fisik dengan sumber berita untuk mendapatkan informasi sahih dari pihak yang bersangkutan. Maka di era publik virtual ini, setiap individu mesti mempunyai stocke of knowledge yang cukup untuk menjaga diri dari kebingunan akibat dari massifikasi data.

Di luar permasalahan tersebut, GNPF sebagai salah satu Gerakan Sosial Baru (GSB) tidaklah berbeda jauh dengan Gerakan Sosial Lama (GSL), terutama terkait dengan candu kuasa. Kedua gerakan tersebut menyasar 
GSB maupun GSL, pastilah menuju pada satu titik, yaitu kekuasaan.

\section{DAFTAR PUSTAKA}

Ahmad Kholili Hasib, Aksi 212 dan 5 Fenomena Lahirnya Generasi Baru Islam Indonesia (https:/ / www.hidayatullah.com/artikel/ghazwul-fikr/read /2016/ 12/08/107231/aksi-212-dan-5-fenomena-lahirnya-generasi-baru-islamindonesia.html, 8 Desember 2016).

Dewi Kartika Sari \& Royke R. Siahainenia, Gerakan Sosial Baru di Ruang Publik Virtual pada Kasus Satinah (Jurnal Ilmu Komunikasi Vol 12, No 1, 2015).

Dwi Wulan Pujiriyani. Re-Imajinasi Ke-Indonesia-An Dalam Konteks "Network Society" (Jurnal Komunitas, Vol 5, No 2, 2013).

F. Budi Hardiman, Seni Memahami - Hermeneutik dari Schleiermacher sampai Derrida (Yogyakarta: Kanisius, 2015).

Hasanuddin, Dinamika dan Pengerucutan Teori Gerakan Sosial (Jurnal Ilmu Pemerintahan Nakhoda Vol 10, No 15, 2011).

Noorhaidi Hasan, Book Review: Islam Politik, Teori Gerakan Sosial, dan Pencarian Model Pengkajian Islam Baru Lintas-Disiplin (Jurnal Al-Jami’ah, Vol. 44, No. 1, 2006 $\mathrm{M} / 1427 \mathrm{H})$.

Rappler, Memahami aksi 212, apakah akan berjalan damai? (https:/ /www.rappler.com /indonesia/berita/154269-aksi-damai-2-desember-silang-monas).

Ressi Dwiana, Mobilisasi Massa dalam Era Network Society (Jurnal Penelitian Komunikasi, Informatika dan Media Massa, Vol 16, No 3, 2013).

Rulli Nasrullah, Internet dan Ruang Publik Virtual, Sebuah Refleksi atas Teori Ruang Publik Habermas (Jurnal Komunikator, Vol 4, No 01, 2012).

S. Yugo Hindarto, GNPF Akan Gelar Aksi Bela Islam 55, (https://www.cnnindonesia.com/ nasional/20170502092141-20211501/gnpf-akan-gelar-aksi-bela-islam-55/, 2 Mei 2017).

Tempo, Dari 411 ke 212 (https://indonesiana.tempo.co/ read/101942/ 2016/ 12/01/Dari-411-ke-212).

Ubedilah Badrun, Gerakan 212 Model Baru Social Movement, (http://www.republika.co.id/ berita/jurnalismewarga/wacana/16/12/05/ohoua1336-gerakan-212-model-baru-socialmovement, 5 Desember 2016).

Wikipedia Bahasa Indonesia, Aksi 112, (https://id.wikipedia.org/wiki/Aksi_112, 11 Pebruari 2017).

Wikipedia Bahasa Indonesia, Aksi 212, (https://id.wikipedia.org/wiki/Aksi_212_ (2017), 21 Pebruari 2017).

Wikipedia Bahasa Indonesia, Aksi 31 Maret, (https://id.wikipedia.org/wiki/ Aksi_ 31_Maret, 31 Maret 2017).

Wikipedia Bahasa Indonesia, Aksi Bela Islam (https://id.wikipedia.org/wiki/ Aksi_Bela_Islam).

http:/ / news.liputan6.com/read/2942281/gnpf-mui-aksi-5-mei-jadi-penutup-aksibela-islam.

https:/ / suarapelita.com/2017/10/30/resmi-gnpf-mui-bubar-ganti-nama-menjadignpf-ulama/. 
Hanifiya: Jurnal Studi Agama-Agama ISSN 2089-8835

Volume 1 Nomor 1 Tahun 2018 